\title{
Spectrum of Morphologic Features of Lupus Nephritis According to Nephrology/Renal Pathology Society (ISN/RPS) Classification
}

Atif A. Hashmi ${ }^{1}$, Javaria Ali ${ }^{1}$, Mansoor Rahman ${ }^{2}$, Anab Rehan Taseer ${ }^{3}$, Jasvindar Kumar ${ }^{4}$, Muhammad $\operatorname{Irfan}^{5}$

1. Histopathology, Liaquat National Hospital and Medical College, Karachi, PAK 2. Internal Medicine, Khyber Medical College, Peshawar, PAK 3. Internal Medicine, Hayatabad Medical Complex, Peshawar, PAK 4. Internal Medicine, Khyber Teaching Hospital, Peshawar, PAK 5. Statistics, Liaquat National Hospital and Medical College, Karachi, PAK

Corresponding author: Atif A. Hashmi, atifhashmi345@gmail.com

\section{Abstract \\ Introduction}

Lupus nephritis is one of the most important secondary glomerulopathy and a significant cause of chronic renal failure. Early diagnosis is key to improved prognosis. The International Society of Nephrology/Renal Pathology Society (ISN/RPS) classification stratifies renal biopsy evaluation in different classes that correlates with clinical renal outcome. In the current study, we aimed to evaluate the proportion of patients in each class of lupus nephritis in our population.

\section{Methods}

We evaluated renal biopsies of 128 patients that fulfilled the clinical and serologic criteria of lupus nephritis. The histologic classification was done according to the ISN/RPS classification, and immunofluorescence studies were performed. Active and chronic lesions were assessed on renal biopsy, and association of different histopatholgic parameters with lupus classes was done.

\section{Results}

The mean age was $28.85 \pm 12.24$ years. Most of the patients were from age group $\leqslant 25$ years $(48.4 \%)$. Active lesions were seen in 66 (51.6\%) patients, with endocapillary hypercellularity being the most common active lesion type, i.e. $81.8 \%$. Chronic lesions were noted in 42 (32.8\%) patients, with glomerular sclerosis being the most common chronic lesion type, i.e. $69 \%$. Majority of the patients belonged to class IV (46.9\%). Females were more likely to present at advanced lupus stage compared to males, and older patients (>50 years) had a higher chance to present at a late stage (class IV and higher). Active lesions were significantly found more frequently in classes III and IV, while chronic lesions were more likely to present in classes III to V.

Received 09/04/2020 Review began 09/06/2020 Review ended 09/11/2020 Published 09/18/2020

() Copyright 2020 Hashmi et al. This is an open access article distributed under the terms of the Creative Commons Attribution License CC-BY 4.0., which permits unrestricted use, distribution, and reproduction in any medium, provided the original author and source are credited.

\section{Conclusion}

We found that a significant proportion of patients of lupus nephritis in our population presents at an advanced stage as more than $60 \%$ patients were of class IV or higher. This signifies lack of appropriate clinical surveillance of patients and assessment of renal functions early in disease course. This also necessitates revision of our locoregional protocols to manage lupus nephritis patients and a need to perform a renal biopsy early in disease course.

Categories: Pathology

Keywords: systemic lupus erythematosis, lupus nephritis, proteinuria, glomerulonephritis, secondary glomerulopathy, nephrology/renal pathology society (isn/rps) classification

\section{Introduction}

Glomerular diseases are one of the most important insidious sources of chronic renal failure [1]. Although primary glomerulopathies remain an important cause [2], most of the cases result from secondary etiologies among which diabetes and systemic lupus erythematosis (SLE) are in top of the list. Renal involvement in SLE is sometimes not readily apparent leading to late presentation and poor outcome. Serologic screening with evaluation of renal parameters like serum creatinine is paramount in early identification of lupus nephritis (LN). Significantly impaired renal parameters like presence of proteinuria warrants further assessment via renal biopsy. Although the cutoff for proteinuria varies, low cutoff like 500 $\mathrm{mg} /$ day is proposed as it is well established that early diagnosis improves prognosis in LN $[3,4]$.

The International Society of Nephrology/Renal Pathology Society (ISN/RPS) proposed a classification for LN that was periodically updated over a period of time [5,6]. Various studies validated the ISN/RPS classification and determined the burden of disease in each class in different populations; however, such studies are 


\section{Cureus}

scarcely available in our population. Therefore, in the current study, we aimed to evaluate the proportion of patients in each class of LN in our population.

\section{Materials And Methods}

It was a cross-sectional retrospective study conducted at Liaquat National Hospital and Medical College, Department of Histopathology, and was carried out from January 2016 till December 2018 for a period of three years. Core renal biopsies from 128 patients fulfilling the histopathological and immunological criteria [7] for the diagnosis of LN were included. Those patients who did not have an adequate biopsy or did not satisfy the histopathological and immunological criteria, or any patient with a pathological disease resembling LN, but had never shown evidence of circulating dsDNA were excluded from the study.

Biopsy specimens were processed for light and immunofluorescence (IMF) microscopy according to standard techniques in our center, including hematoxylin and eosin, periodic acid-Schiff, silver, and trichrome staining (Figures 1-4).

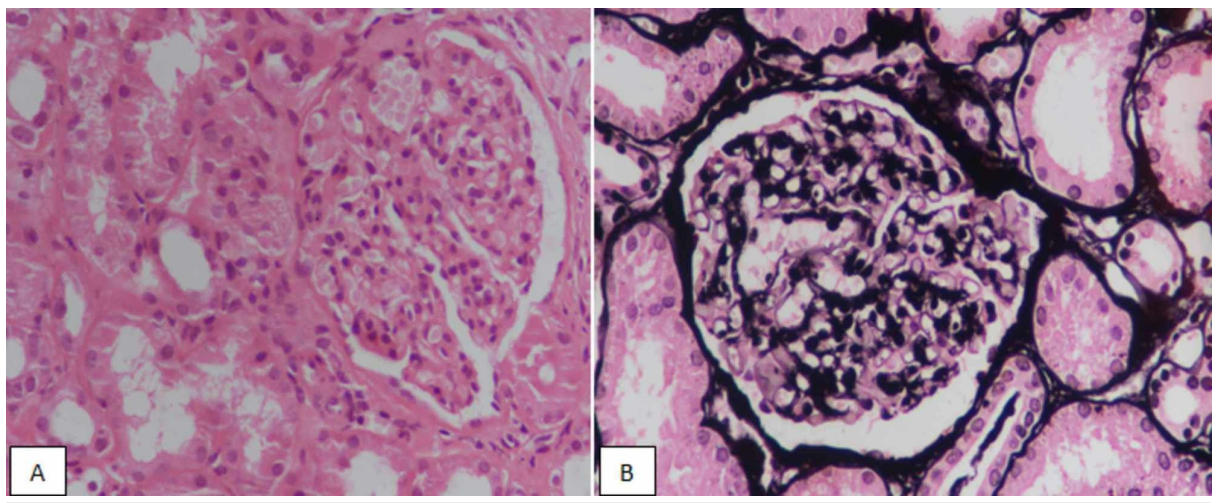

FIGURE 1: Class II lupus nephritis. (A) Hematoxylin and eosin staining at $\times \mathbf{4 0 0}$ highlighting mesangial proliferation. (B) Silver staining demonstrating lack of segmental sclerosis or membrane thickening.

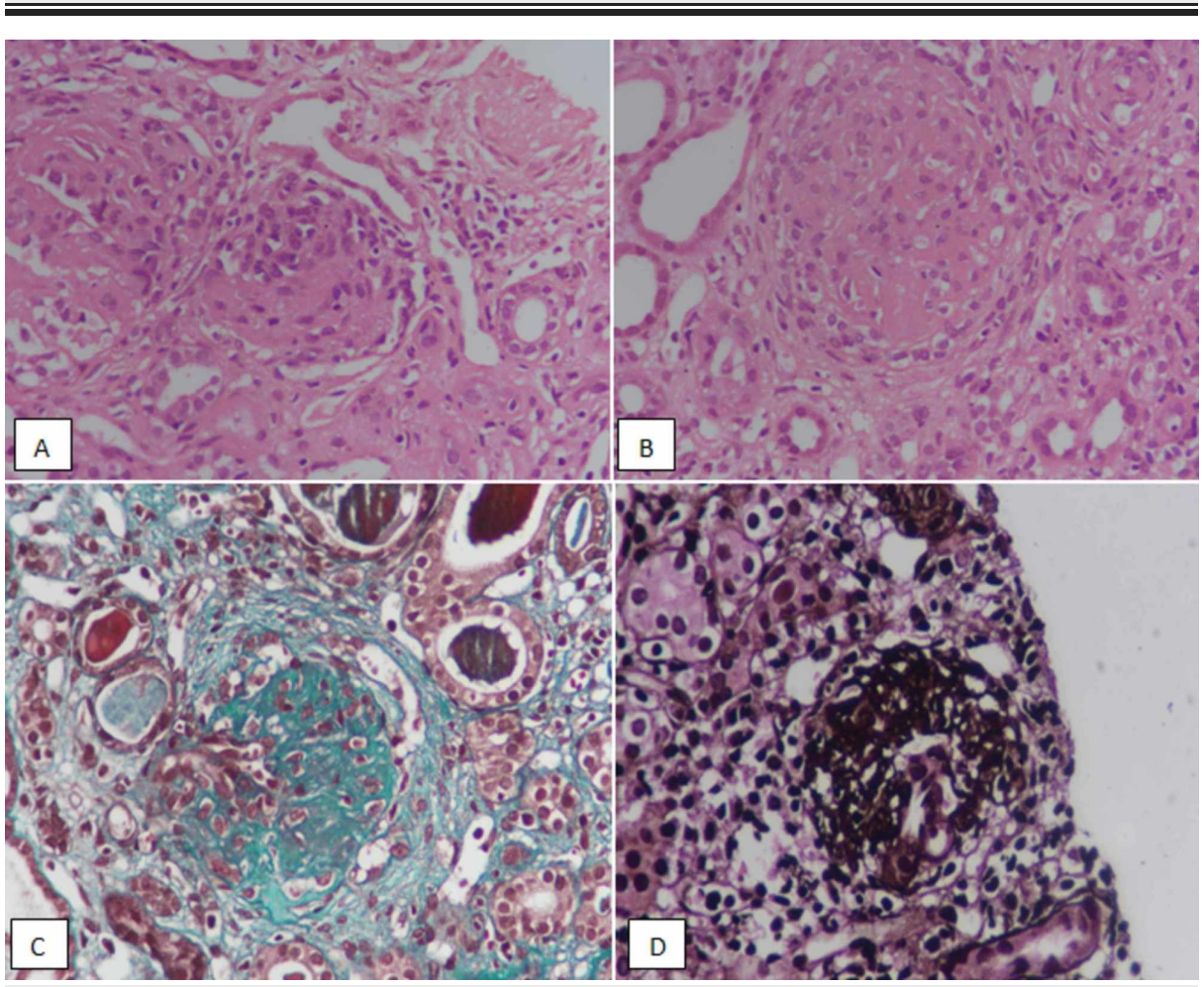

FIGURE 2: Class III lupus nephritis. (A, B) Hematoxylin and eosinstained sections at $\times \mathbf{4 0 0}$ demonstrating segmental sclerosing lesions in glomeruli. (C) Trichome stain highlighting segmental sclerosis. (D) 


\section{Cureus}

Silver stain showing segmental sclerosis in a glomerulus.

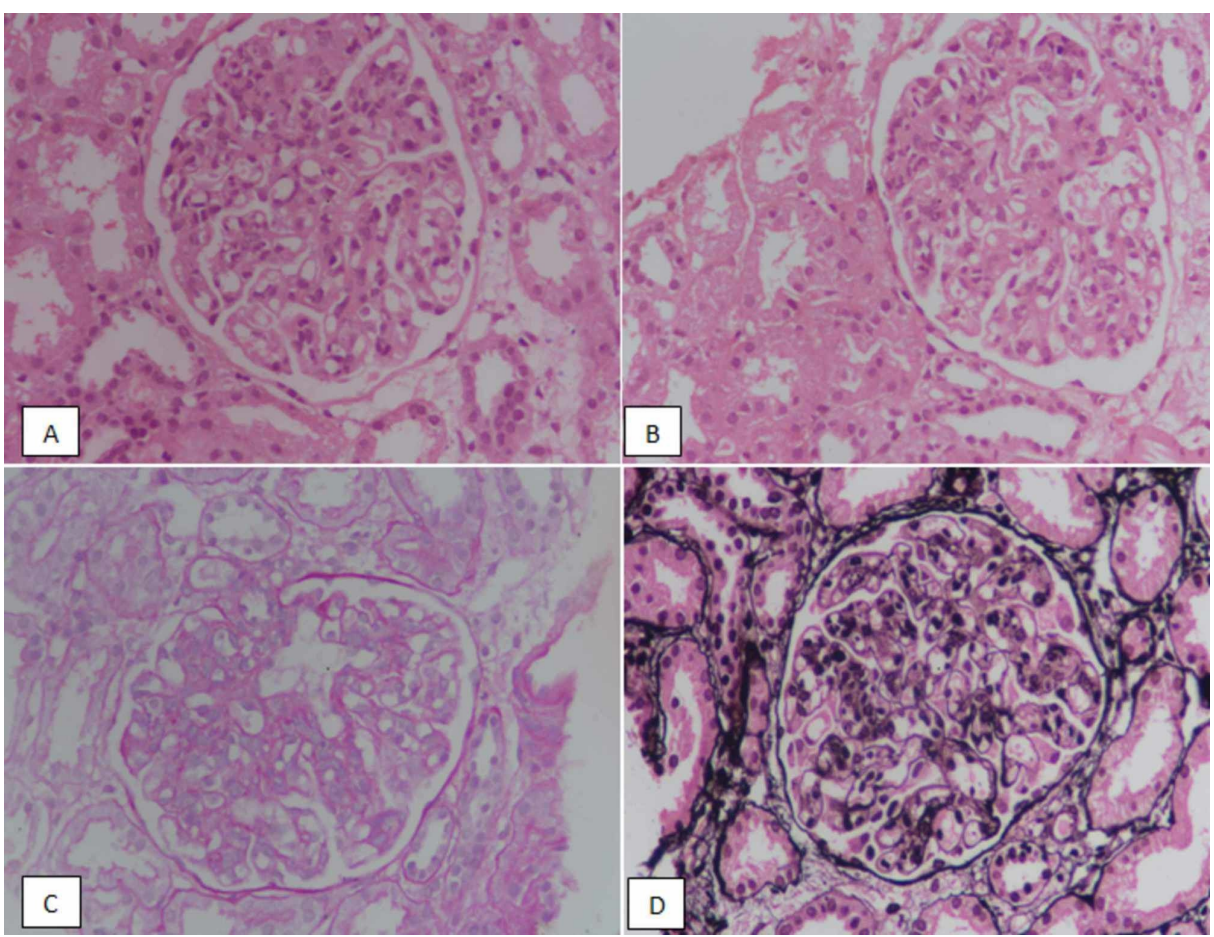

FIGURE 3: Class IV lupus nephritis. (A, B) Hematoxylin and eosin staining at $\times \mathbf{4 0 0}$ highlighting endocapillary proliferation. (C) Periodic acid-schiff (PAS) staining demonstrating endocapillary proliferation and lack of membrane thickening. (D) Silver staining showing lack of membrane thickening.

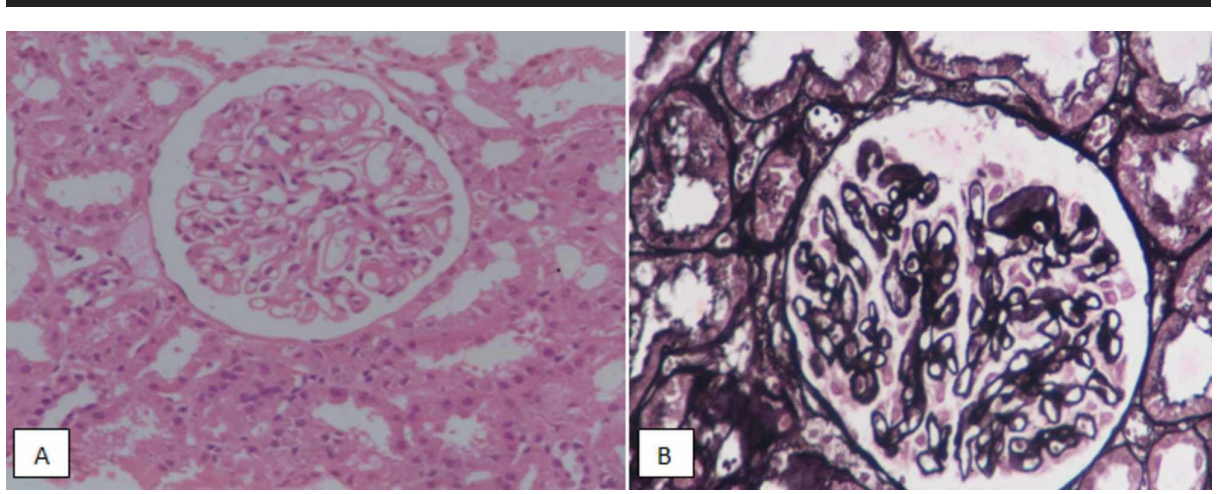

FIGURE 4: Class V lupus nephritis. (A) Hematoxylin and eosin staining at $\times \mathbf{4 0 0}$ highlighting membrane thickening. (B) Silver staining demonstrating membrane thickening.

The histopathological classification of LN was done according to the ISN/RSP classification of LN from classes I to VI [8].

IMF scoring was interpreted by a senior consultant histopathologist on an intensity score of 0 to $3+$, pattern was identified as linear or granular, and distribution of immune deposits was labeled as mesangial or membranous.

For data analysis, IBM SPSS Statistics for Windows, Version 20.0 (IBM, Armonk, NY) was used. Mean and standard deviation were evaluated for quantitative variables. Frequency and percentage were evaluated for 


\section{Cureus}

qualitative variables. Chi-square test and Fisher's exact test were applied to determine association as appropriate. P-value $\leqslant 0.05$ was considered significant.

\section{Results}

Among 128 patients, 20 (15.6\%) were male and 108 (84.4\%) were female patients. The mean age was $28.85 \pm 12.24$ years. Most of the patients were from age group $\leqslant 25$ years $(48.4 \%)$. Active lesions were seen in 66 (51.6\%) patients, with endocapillary hypercellularity being the most common active lesion type, i.e. $81.8 \%$. Chronic lesions were noted in 42 (32.8\%) patients, with glomerular sclerosis being the most common chronic lesion type, i.e. 69\%. Majority of the patients belonged to class IV (46.9\%) (Table 1, Figure 5).

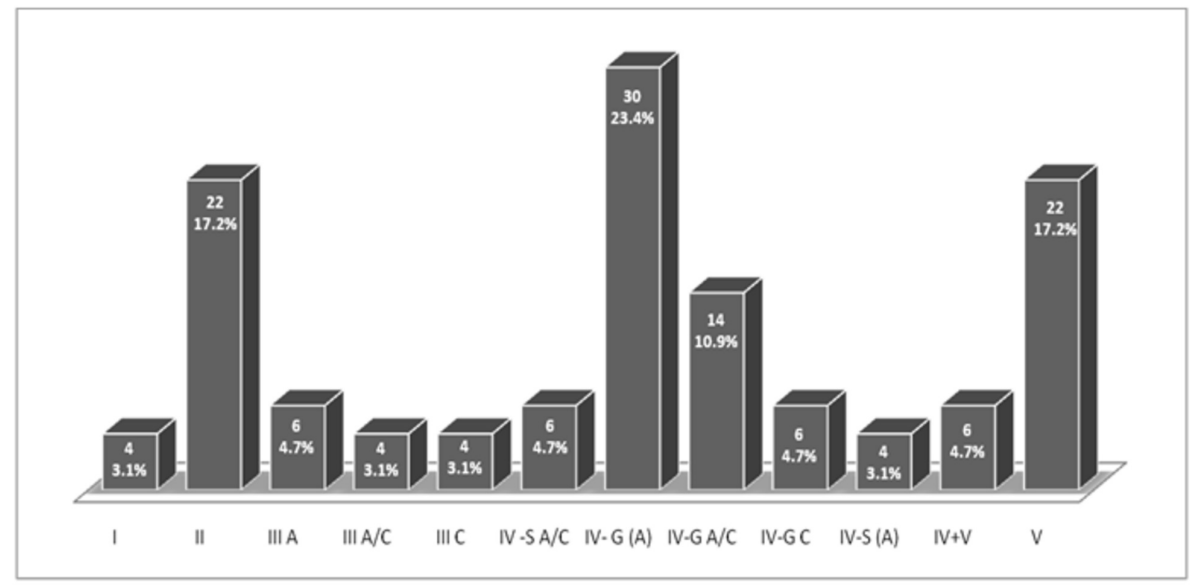

FIGURE 5: Distribution of patients into different classes according to the Nephrology/Renal Pathology Society (ISN/RPS) Classification. 


\section{Cureus}

\begin{tabular}{|c|c|c|}
\hline & Characteristic & Frequency (\%) \\
\hline \multicolumn{3}{|l|}{ Age (years) } \\
\hline Mean $\pm S D$ & & $28.85 \pm 12.24$ \\
\hline \multirow{3}{*}{ Groups } & $\leq 25$ years & $62(48.4)$ \\
\hline & $26-50$ years & $60(46.9)$ \\
\hline & $>50$ years & $6(4.7)$ \\
\hline \multirow{2}{*}{ Gender } & Male & $20(15.6)$ \\
\hline & Female & $108(84.4)$ \\
\hline \multirow{2}{*}{ Active lesions } & Present & $66(51.6)$ \\
\hline & Absent & $62(48.4)$ \\
\hline \multirow{3}{*}{ Active lesions type $(n=66)$} & Endocapillary hypercellularity & $54(81.8)$ \\
\hline & Karyorrhexis & $8(12.1)$ \\
\hline & Fibrinoid necrosis & $4(6.1)$ \\
\hline \multirow{2}{*}{ Chronic lesions } & Present & $42(32.8)$ \\
\hline & Absent & $86(67.2)$ \\
\hline \multirow{3}{*}{ Chronic lesions type $(n=42)$} & Glomerular sclerosis & $29(69)$ \\
\hline & Fibrous adhesions & $9(21)$ \\
\hline & Fibrous crescents & $4(9.5)$ \\
\hline \multirow{6}{*}{ Class } & Class I & $4(3.1)$ \\
\hline & Class II & $22(17.2)$ \\
\hline & Class III & $14(10.9)$ \\
\hline & Class IV & $60(46.9)$ \\
\hline & Class V & $22(17.2)$ \\
\hline & Class IV+V & $6(4.7)$ \\
\hline
\end{tabular}

TABLE 1: Clinicopathologic characteristics of studied population

Most of the cases showed full-house IMF pattern irrespective of class. Moreover, IgA and IgM were more frequently expressed in classes I, II, and V compared to classes III and IV (Table 2). 


\section{Cureus}

\begin{tabular}{|c|c|c|c|c|c|c|c|c|}
\hline & \multicolumn{6}{|l|}{ n (\%) } & \multirow[b]{2}{*}{ Total } & \multirow{2}{*}{ P-Value } \\
\hline & $\begin{array}{l}\text { Class I } \\
(n=4)\end{array}$ & $\begin{array}{l}\text { Class II } \\
(n=22)\end{array}$ & $\begin{array}{l}\text { Class III } \\
(n=14)\end{array}$ & $\begin{array}{l}\text { Class IV } \\
(\mathrm{n}=60)\end{array}$ & $\begin{array}{l}\text { Class V } \\
(n=22)\end{array}$ & $\begin{array}{l}\text { Class IV+Class V } \\
(n=6)\end{array}$ & & \\
\hline $\lg G$ & $4(100)$ & 20 (90.9) & $10(71.4)$ & $46(76.7)$ & $22(100)$ & $6(100)$ & $108(84.4)$ & $0.049^{\star}$ \\
\hline IgM & $4(100)$ & $22(100)$ & $14(100)$ & 56 (93.3) & $22(100)$ & $6(100)$ & $124(96.9)$ & $0.456^{\star \star}$ \\
\hline $\lg A$ & $4(100)$ & $18(81.8)$ & 12 (85.7) & $48(80)$ & $22(100)$ & $0(0)$ & 104 (81.3) & $0.000^{\star}$ \\
\hline C1q & $4(100)$ & $22(100)$ & $14(100)$ & $22(100)$ & $6(100)$ & $6(100)$ & 128 (100) & N/A \\
\hline C3c & $4(100)$ & $20(90.9)$ & 12 (85.7) & 56 (93.3) & $22(100)$ & $6(100)$ & $120(93.8)$ & $0.550^{\star \star}$ \\
\hline
\end{tabular}

TABLE 2: Immunofluorescence pattern in different classes of lupus nephritis

Fisher's exact test was applied

*Significant as $<0.05$

**Not significant as $>0.05$

Females were more likely to present at advanced lupus stage compared to males and older patients $(>50$ years) had a higher chance to present at a late stage (class IV and higher). Active lesions were significantly found more frequently in classes III and IV, while chronic lesions were more likely to present in classes III to V (Table 3).

\begin{tabular}{|c|c|c|c|c|c|c|c|c|}
\hline & & \multicolumn{6}{|l|}{ n (\%) } & \multirow{2}{*}{$\begin{array}{l}\text { P- } \\
\text { Value }\end{array}$} \\
\hline & & $\begin{array}{l}\text { Class I } \\
(n=4)\end{array}$ & $\begin{array}{l}\text { Class II } \\
(\mathrm{n}=22)\end{array}$ & $\begin{array}{l}\text { Class III } \\
(n=14)\end{array}$ & $\begin{array}{l}\text { Class IV } \\
(\mathrm{n}=60)\end{array}$ & $\begin{array}{l}\text { Class V } \\
(n=22)\end{array}$ & $\begin{array}{l}\text { Class IV+Class V } \\
(\mathrm{n}=6)\end{array}$ & \\
\hline \multirow{2}{*}{ Gender } & Male & $2(50)$ & $0(0)$ & 2 (14.3) & $10(16.7)$ & $6(27.3)$ & $0(0)$ & \multirow{2}{*}{$0.032^{*}$} \\
\hline & Female & $2(50)$ & $22(100)$ & 12 (85.7) & $50(83.3)$ & $16(72.7)$ & $6(100)$ & \\
\hline \multirow{3}{*}{ Age group } & $\leq 25$ years & $2(50)$ & 16 (72.7) & $10(71.4)$ & $26(43.3)$ & $6(27.3)$ & 2 (33.3) & \multirow{3}{*}{$0.036^{*}$} \\
\hline & $\begin{array}{l}26-50 \\
\text { years }\end{array}$ & $2(50)$ & $6(27.3)$ & $4(28.6)$ & $28(46.7)$ & 16 (72.7) & $4(66.7)$ & \\
\hline & $>50$ years & $0(0)$ & $0(0)$ & $0(0)$ & $6(10)$ & $0(0)$ & $0(0)$ & \\
\hline \multirow{2}{*}{ Active lesions } & Present & $0(0)$ & $0(0)$ & $10(71.4)$ & $54(90)$ & $0(0)$ & 2 (33.3) & \multirow{2}{*}{$<0.001 *$} \\
\hline & Absent & 4 (100) & 22 (100) & 4 (28.6) & $6(10)$ & 22 (100) & $4(66.7)$ & \\
\hline \multirow{2}{*}{$\begin{array}{l}\text { Chronic } \\
\text { lesions }\end{array}$} & Present & $0(0)$ & $0(0)$ & $8(57.1)$ & $28(46.7)$ & $0(0)$ & $6(100)$ & \multirow{2}{*}{$<0.001^{*}$} \\
\hline & Absent & $4(100)$ & $22(100)$ & $6(42.9)$ & $32(53.3)$ & $22(100)$ & $0(0)$ & \\
\hline
\end{tabular}

\section{TABLE 3: Association of different clinicopathologic characteristics with lupus nephritis classes}

Fisher's exact test was applied

*Significant as $<0.05$.

**Not significant as $>0.05$

\section{Discussion}

In the present study, we found that a significant proportion of patients of LN in our population presents at 
an advanced stage as more than 60\% patients were of class IV or higher. Moreover, we found that active lesions are more likely to be present in classes III and IV compared to other classes.

Our results show that females were more likely to present at advanced lupus stage compared to males and older patients ( $>50$ years) had a higher chance to present at a late stage (class IV and higher).

Active and chronic lesions are defined prognostic parameters in the ISN/RSP classification; we found that class III and IV patients were more likely to show active lesions on renal biopsy, while class III to V patients were more prone to have chronic lesions.

Various studies have validated the clinical importance of the ISN/RSP classification of LN. Studies have shown that, apart from classes I to VI, histological parameters like endocapillary hypercellularity, fibrinoid necrosis, and cellular crescents correlate with clinical renal outcome [9]. We found the presence of such active lesions in $51.6 \%$ of the cases.

Asian patients with SLE are shown to have higher frequency of kidney involvement compared to Western countries [10]. Moreover, more severe renal impairment was noted in Asian people suffering from LN [11]. A study conducted in Thailand, including 569 patients, found that $43.6 \%$ patients had nephrotic range proteinuria. Renal biopsy was done in 314 patients, among which $61.5 \%$ patients had a diffuse proliferative (class IV) pattern [12]. Although in our study we did not assessed frequency of renal involvement in SLE patients, we also found quite a high percentage of diffuse proliferative LN in our population, i.e. $46.9 \%$, and $68.4 \%$ patients had IV or higher pattern (IV, V, and IV+V). Similarly, an Iranian study found an even higher frequency of class IV LN, i.e. 70.7\% with 6.1\% mortality in LN patients [13]. A multiethinic Asian study with more than 70\% Chinese patients reported about two-thirds of LN patients with >class III pattern [14]. Demographic difference of frequency and severity of renal involvement of LN was also pointed out in a retrospective analysis [15]. This brief literature review clearly indicates grave disease severity in Asian LN patients and stipulates better management protocols and a need of early diagnosis.

Our study can be viewed with a few limitations. Most importantly, clinical follow-up of the patients was not available to correlate with histological findings, as high disease mortality was seen in other studies conducted in Asia. Therefore, we recommend more large-scale clinical studies to be done in our population to evaluate frequency of renal involvement in SLE patients and disease outcome/mortality in this subset of patients.

\section{Conclusions}

We found that a significantly higher proportion of our population with LN presents at an advanced stage according to the ISN/RSP LN classification. This signifies lack of appropriate clinical surveillance of patients and assessment of renal functions early in disease course and high threshold for performing a renal biopsy.

\section{Additional Information}

\section{Disclosures}

Human subjects: All authors have confirmed that this study did not involve human participants or tissue. Animal subjects: All authors have confirmed that this study did not involve animal subjects or tissue. Conflicts of interest: In compliance with the ICMJE uniform disclosure form, all authors declare the following: Payment/services info: All authors have declared that no financial support was received from any organization for the submitted work. Financial relationships: All authors have declared that they have no financial relationships at present or within the previous three years with any organizations that might have an interest in the submitted work. Other relationships: All authors have declared that there are no other relationships or activities that could appear to have influenced the submitted work.

\section{References}

1. Floege J, Amann K: Primary glomerulonephritides. Lancet. 2016, 387:2036-2048. 10.1016/S01406736(16)00272-5

2. Hashmi AA, Hussain ZF, Edhi MM, Mumtaz S, Faridi N, Khan M: Insight to changing morphologic patterns of glomerulopathy in adult Pakistani patients: an institutional perspective. BMC Res Notes. 2016, 9:73. 10.1186/s13104-016-1876-y

3. Fiehn C, Hajjar Y, Mueller K, Waldherr R, Ho AD, Andrassy K: Improved clinical outcome of lupus nephritis during the past decade: importance of early diagnosis and treatment. Ann Rheum Dis. 2003, 62:435-439. 10.1136/ard.62.5.435

4. Almaani S, Meara A, Rovin BH: Update on lupus nephritis. Clin J Am Soc Nephrol. 2017, 12:825-835. 10.2215/CJN.05780616

5. Weening JJ, D'Agati VD, Schwartz MM, et al.: The classification of glomerulonephritis in systemic lupus erythematosus revisited. J Am Soc Nephrol. 2004, 15:241-250. 10.1097/01.asn.0000108969.21691.5d

6. Bajema IM, Wilhelmus S, Alpers CE, et al.: Revision of the International Society of Nephrology/Renal Pathology Society classification for lupus nephritis: clarification of definitions, and modified National Institutes of Health activity and chronicity indices. Kidney Int. 2018, 93:789-796. 10.1016/j.kint.2017.11.023 


\section{Cureus}

7. Giannakakis K, Faraggiana T: Histopathology of lupus nephritis. Clin Rev Allergy Immunol. 2011, 40:170180. 10.1007/s12016-010-8207-1

8. Wilhelmus S, Alpers CE, Cook HT, et al.: The revisited classification of GN in SLE at 10 years: time to reevaluate histopathologic lesions. J Am Soc Nephrol. 2015, 26:2938-2946. 10.1681/ASN.2015040384

9. Tao J, Wang H, Yu XJ, et al.: A validation of the 2018 revision of International Society of Nephrology/Renal Pathology Society Classification for lupus nephritis: a cohort study from China. Am J Nephrol. 2020, 51:483492. 10.1159/000507213

10. Jakes RW, Bae SC, Louthrenoo W, Mok CC, Navarra SV, Kwon N: Systematic review of the epidemiology of systemic lupus erythematosus in the Asia-Pacific region: prevalence, incidence, clinical features, and mortality. Arthritis Care Res (Hoboken). 2012, 64:159-168. 10.1002/acr.20683

11. Yap DY, Tang CS, Ma MK, Lam MF, Chan TM: Survival analysis and causes of mortality in patients with lupus nephritis. Nephrol Dial Transplant. 2012, 27:3248-3254. 10.1093/ndt/gfs073

12. Shayakul C, Ong-aj-yooth L, Chirawong P, et al.: Lupus nephritis in Thailand: clinicopathologic findings and outcome in 569 patients. Am J Kidney Dis. 1995, 26:300-307. 10.1016/0272-6386(95)90650-9

13. Fatemi A, Kazemi M, Sayedbonakdar Z, Farajzadegan Z, Karimzadeh H, Moosavi M: Long-term outcome of biopsy-proven lupus nephritis in Iran. Int J Rheum Dis. 2013, 16:739-746. 10.1111/1756-185X.12228

14. Lim CC, Tan HZ, Hao Y, Chin YM, Woo KT, Chan CM, Choo JCJ: Long-term renal outcomes in multi-ethnic Southeast Asians with lupus nephritis: a retrospective cohort study. Intern Med J. 2018, 48:1117-1123. 10.1111/imj.13960

15. Seligman VA, Lum RF, Olson JL, Li H, Criswell LA: Demographic differences in the development of lupus nephritis: a retrospective analysis. Am J Med. 2002, 112:726-729. 10.1016/s0002-9343(02)01118-x 